\title{
KUALITAS PELAYANAN PEMBUATAN TANDA IZIN MASUK DAERAH KEAMANAN TERBATAS ATAU KARTU PAS ORANG DI UNIT PENYELENGGARA BANDAR UDARA TJILIK RIWUT PALANGKA RAYA
}

\author{
Quality of Service in Making a Limited Security Entry Permit or Person Pas Pas in the \\ Unit of Tjilik Riwut Airport in Palangka Raya
}

\author{
Karyadi* \\ Miftahul Hestiana
}

Universitas Muhammadiyah Palangkaraya, Palangka Raya, Central Kalimantan, Indonesia

email:

karyadi@umpalangkaraya.ac.id

\section{Kata Kunci:}

Kualitas Pelayanan

Kartu Pas Orang

Unit Penyelenggara Bandar

Udara

Keywords:

Service quality

Pass People Card

Airport Organizing Unit

Accepted

June 2016

\section{Published}

October 2016

\begin{abstract}
Abstrak
Tujuan dari penelitian adalah untuk menjelaskan dan mendeskripsikan tentang Kualitas Pelayanan Pembuatan Tanda Izin Masuk Daerah Keamanan Terbatas atau Kartu Pas Orang Di Kantor Unit Penyelenggara Bandar Udara Kelas I Tjilik Riwut Palangka Raya. Jenis penelitian yang digunakan dalam penelitian ini adalah deskriptif dengan metode penelitian kualitatif. Jenis data dalam penelitian ini adalah data primer yaitu, dari para petugas pembuatan Tanda Izin Masuk Daerah Keamanan Terbatas atau Kartu Pas dan para pemohon. Sedangkan data sekunder berasal dari dokumendokumen resmi yang terkait dengan penelitian ini seperti SOP Pas Orang. Tehnik pengumpulan data menggunakan wawancara, observasi, dan dokumentasi. Fokus penelitiannya adalah Pembuatan Tanda Izin Masuk Daerah Keamanan Terbatas atau Kartu Pas Orang di Kantor Unit Penyelenggara Bandar Udara Kelas I Tjilik Riwut Palangka Raya. Berdasarkan hasil penelitian menunjukkan bahwa kualitas pelayanan yang diberikan oleh pihak Kantor Unit Penyelenggara Bandar Udara Kelas I Tjilik Riwut Palangka Raya masih belum maksimal, karena dari lima indikator kualitas pelayanan ada tiga indikator yang belum berjalan dengan baik yaitu indikator Tangibles, Reliability, dan Empathy sedangkan dua indikator yang sudah berjalan dengan baik adalah indikator Responsiveness dan Assurance.
\end{abstract}

\section{PENDAHULUAN}

Pada hakikatnya tugas pokok pemerintahan sebagai organisasi publik adalah memberikan pelayanan kepada masyarakatnya, sehingga aparat pemerintah memiliki kewajiban dan tanggung jawab untuk memberikan pelayanan publik dengan baik dan dapat memuaskan semua pihak. Namun, hingga saat ini masih saja ditemukan pelayanan publik yang belum maksimal tak terkecuali pelayanan dalam pembuatan Tanda Izin
Masuk Daerah Keamanan Terbatas atau lebih dikenal dengan sebutan kartu Pas Orang di Kantor Unit Penyelenggara Bandar Udara Tjilik Riwut Palangka Raya. Permasalahan dalam pembuatan kartu pas orang di Bandar Udara Tjilik Riwut Palangka Raya yaitu masalah waktu pembuatan yang tidak sesuai dengan waktu yang telah ditentukan sera mengenai persyaratan pengajuan permohonan pembuatan kartu pas bandar udahra. Kemudian waktu pembautan kartu pas tida sesuai 
dengan waktu yang ditentukan di karenakan komputer atau alat cetak kartu pas Bandar Udara sring mengalami kerusakan.

Menurut Lewis \& Booms (Tjiptono, 2012:157) mengatakan bahwa "secara sederhana, kualitas layanan bisa diartikan sebagai ukuran seberapa bagus tingkat layanan yang diberikan mampu sesuai dengan ekspektasi pelanggan.” Agung kurniawan (Pasolong,2008:128) mengatakan bahwa "pelayanan publik adalah pemberian pelayanan (melayani) keperluan orang lain atau masyarakat yang mempunyai kepentingan pada organisasi yang sesuai dengan aturan pokok dan tata cara yang telah ditetapkan. Menurut Parasuraman (Lupiyoadi, 200I:148) ada lima indikator untuk mengukur kualitas pelayanan meliputi :

I. Tangibles (bukti fisik)

2. Reliability (kehandalan),

3. Responsiveness (daya tanggap)

4. Assurance (jaminan)

5. Empathy (perhatian)

Peraturan Menteri Perhubungan Republik Indonesia Nomor 98 Tahun 2016 menyebutkan tentang Standar Pelayanan pada Kantor Unit Penyelenggara Bandar Udara Tjilik Riwut Palangkaraya yang meliputi: (a). Proses Keberangkatan dan Kedatangan Penumpang; (b). Pelayanan Jasa Pendaratan, Penempatan dan Penyimpanan Pesawat Udara (PJP4U); (c). Pelayanan Jasa Penggunaan Bandar Udara di Luar Jam Operasi Bandar Udara; (d). Pelayanan Jasa Penggunaan Bandar Udara Alternatif (Alternate Aerodrome); (e). Pelayanan Jasa Pemakaian Tempat Pelaporan Keberangkatan; (f). Pelayanan Jasa Kargo dan Pos Pesawat Udara; (g). Pelayanan Jasa Penggunaan Sarana dan Prasarana di Bandar Udara berdasarkan Tugas dan Fungsi; dan (h). Izin masuk daerah terbatas dan daerah keamanan terbatas. Pas Bandar Udara sendiri merupakan tanda izin masuk di bandara. Pas Bandar Udara bukan hanya sebagai tanda izin masuk tetapi merupakan security control bagi sekurity bandara untuk mengontrol atau memantau orang/kendaraan bermotor di, dan, ke area terbatas, sehingga keamanan dan keselamatan di Bandar Udara lebih terjamin.

\section{METODOLOGI}

Berdasarkan tujuan penelitian, jenis penelitian ini adalah deskriptif dengan menggunakan pendekatan kualitatif karena penelitian ini menggambarkan keadaan subjek dan obyek penelitian berdasarkan fakta-fakta yang terjadi dalam masyarakat dan data-data yang diperoleh dari informan aupun dari pengalaman. Selain itu, penelitian ini menggunakan pendekatan deskriptif dikarenakan adanya pendekatan yang bertujuan untuk mengidentifikasi dan mendeskripsikan mengenai pembuatan kartu Pas Bandar Udara.

\section{HASIL DAN PEMBAHASAN}

Tangibles

Berdasarkan hasil penelitian di lapangan dan wawancara dengan petugas pembuatan kartu Pas Bandara dan pemohon diketahui pelayanan di Kantor Unit Penyelenggara Bandar Udara Tjilik Riwut Palangka Raya belum sesuai dengan indikator Tangibles. Hal ini dikarenakan dari pengamatan yang ada diketahui bahwa pihak Kantor Unit Penyelenggara Bandar Udara Tjilik Riwut Palangka Raya hanya mempuyai satu komputer khusus untuk mencetak kartu Pas. Padahal diketahui bahwa komputer khusus untuk mencetak kartu Pas ini adalah sarana yang paling penting dalam pelayanan pembuatan kartu Pas.

Reliability

Dari hasil penelitian yang dilakukan diketahui bahwa pelayanan di Kantor Unit Penyelenggara Bandar Udara Tjilik Riwut Palangka Raya tidak sesuai dengan indikator Reliability, hal ini dikarenakan masih adanya keterlambatan dalam penyelesaian pembuatan kartu Pas Bandar Udara. Dan diketahui bahwa keterlambatan 
tersebut karena mereka hanya mempunyai satu komputer yang khusus untuk mencetak kartu Pas sedangkan komputer tersebut sering rusak dan harus memanggil ahli dari luar untuk memperbaikinya serta petugas hanya akan memproses berkas yang lengkap.

\section{Responsiveness}

Berdasarkan hasil wawancara diatas diketahui bahwa untuk indikator Responsiveness, petugas cukup tanggap dalam memberikan pelayananan hal ini dilihat dari cukup baiknya tanggapan dari pemohon terhadap petugas. Bagi petugas yang memang kerjaannya khusus di dalam ruangan dan tidak ada hal yang mendesak dengan urusan diluar kantor mereka biasanya selalu ada di tempat dan bergantian menjaga ruangan.

\section{Assurance}

Berdasarkan hasil wawancara diatas, diketahui bahwa untuk indikator Assurance sikap para petugas Kantor Unit Penyelenggara Bandar Udara Tjilik Riwut Palangka Raya sudah baik, ramah dan sopan serta memberikan kemudahan kepada pemohon untuk mendapatkan pelayanan pembuatan kartu Pas dengan syarat berkas harus lengkap.

Empathy

Berdasarkan hasil wawancara didapatkan bahwa dalam berkomunikasi antara petugas dan pemohon belum terjalin dengan baik karena kadang ada perbedaan persepsi antara petugas dengan pemohon ditambah lagi ada pemohon yang menggunakan bahasa daerah sedangkan petugas yang melayani tidak bisa.

\section{KESIMPULAN}

Berdasarkan hasil penelitian dan pembahasan ini, peneliti menyimpulkan bahwa Kualitas Pelayanan dalam Pembuatan Tanda Izin Masuk Daerah Keamanan Terbatas atau Kartu Pas Orang di Bandar Udara Tjilik Riwut Palangka Raya masih belum maksimal karena dari lima indikator terdapat tiga yang belum sesuai dengan indikator Parasuraman, yaitu indikator Tangibles, Reliability dan Empathy.

\section{REFERENSI}

Bernardianto, R.B., Arifin, M. 2016. Kualitas Pelayanan Pencatatan Nikah Berbasis Teknologi Informasi Di Kabupaten Pulang Pisau Provinsi Kalimantan Tengah. Pencerah Publik. 3(2): 19 32.

Darmanto dkk. 2009. Sistem Administrasi Negara Kesatuan Republik Indonesia. Jakarta: Universitas Terbuka.

Dwiyanto, Agus. 2008. Mewujudkan Good Governance Melalui Pelayanan Publik. Yogyakarta: Gadjah Mada University Press.

Handayani, I.T. 20I5. Kualitas Pelayanan Kenaikan Pangkat Pegawai Negeri Sipil Oleh Badan Kepegawaian Daerah Kabupaten Gunung Mas. Anterior Jurnal. I 5(I): I-9.

Hutasoit. 20II. Pelayanan Public Teori dan Aplikasi. Jakarta Timur: Magnascript Publishing.

Komarudin. 2014. Reformasi Birokrasi dan Pelayanan Publik, Jakarta: Ganesindo.

Lampiran Peraturan Menteri Pendayagunaan Aparatur Negara dan Reformasi Birokrasi Nomor 15 Tahun 2014 Tentang Pedoman Standar Pelayanan.

Lupiyoadi, Rambat. 200I. Manajemen Pemasaran Jasa. Jakarta: Salemba Empat.

Moenir H.A.S. 2002. Manajemen Pelayanan Publik. Jakarta : Bumi Aksara.

Moleong, Lexy J. M.A., 2012. Metodologi Penelitian Kualitatif: ROSDA.

Ndraha Taliziduhu. 20 I I. Kybernologi 20I5. Tangerang: Sirao Credentia Center.

Nurhasanah, N., Manto, D. 2016. Kualitas Pelayanan Pembuatan Paspor di Kantor Imigrasi Kelas I Palangka Raya. Pencerah Publik. 3(2):39-47.

Pasolong, Harbani. 2008. Teori Administrasi Publik, Bandung: Alfabeta. 